Cite this: Dalton Trans., 2013, 42, 15906

Received 26th June 2013,

Accepted 24th July 2013

DOI: $10.1039 / \mathrm{c} 3 \mathrm{dt} 51709 \mathrm{~h}$

\section{Relative anion binding affinity in a series of interpenetrated coordination cages $\dagger$}

\author{
Marina Frank, ${ }^{a}$ Johannes M. Dieterich, ${ }^{\mathrm{b}}$ Sabrina Freye, ${ }^{\mathrm{a}}$ Ricardo A. Matab and \\ Guido H. Clever*a
}

www.rsc.org/dalton

Previously, we have reported on the quantitative self-assembly of a series of interpenetrated double-cages $\left[\mathrm{Pd}_{4}\right.$ Ligand $\left.{ }_{8}\right]$ with ligands based on various organic backbones. For dibenzosuberone-based cages it was shown that anion binding in the outer two pockets follows an allosteric mechanism. Herein we wish to report the anion binding capabilities of three related phenothiazine cages. We present a systematic comparison of the relative halide $\left(\mathrm{Cl}^{-}\right.$and $\left.\mathrm{Br}^{-}\right)$binding affinities and the structural rearrangements of four double-cages based on NMR titrations, NOESY experiments and electronic structure calculations.

Anion binding is of tremendous importance, both in biological systems and in artificial supramolecular assemblies such as sensors and transporters. ${ }^{1}$ Many artificial anion binders are based on positively charged coordination cages ${ }^{2}$ whose binding affinity and guest selectivity may be altered by structural changes. ${ }^{3}$

Recently, we have reported the anion binding capabilities of two interpenetrated coordination cages ${ }^{4}$ that quantitatively assemble from eight dibenzosuberone-based bis-monodentate pyridyl ligands and four square-planar coordinated $\operatorname{Pd}($ II) cations (Fig. 1a). ${ }^{5}$ Depending on the size of the templating anion inside the central cavity, anions of different sizes ranging from the small chloride ${ }^{5 a}$ to the large perrhenate ${ }^{5 b}$ were selectively incorporated into the outer two pockets. In all cases, anion binding was found to proceed in an allosteric fashion with positive cooperativity. Experimental ${ }^{6}$ (DOSY and NOESY) as well as computational ${ }^{7}$ results have shown that the anion binding is accompanied by a compression of the interpenetrated dimer along the $\mathrm{Pd}_{4}$-axis ( $\Delta d$ in Fig. 1a).

In another recent work, we showed that the redox-active heterocycle phenothiazine and two of its S-oxygenated derivatives are

${ }^{a}$ Institut für Anorganische Chemie, Georg-August Universität Göttingen, Tammannstr. 4, 37077 Göttingen, Germany.E-mail: gclever@gwdg.de; http://www.clever-lab.de

${ }^{b}$ Institut für Physikalische Chemie, Georg-August Universität Göttingen, Tammannstr. 6, 37077 Göttingen, Germany

†Electronic supplementary information (ESI) available. See DOI: 10.1039/ c3dt51709h
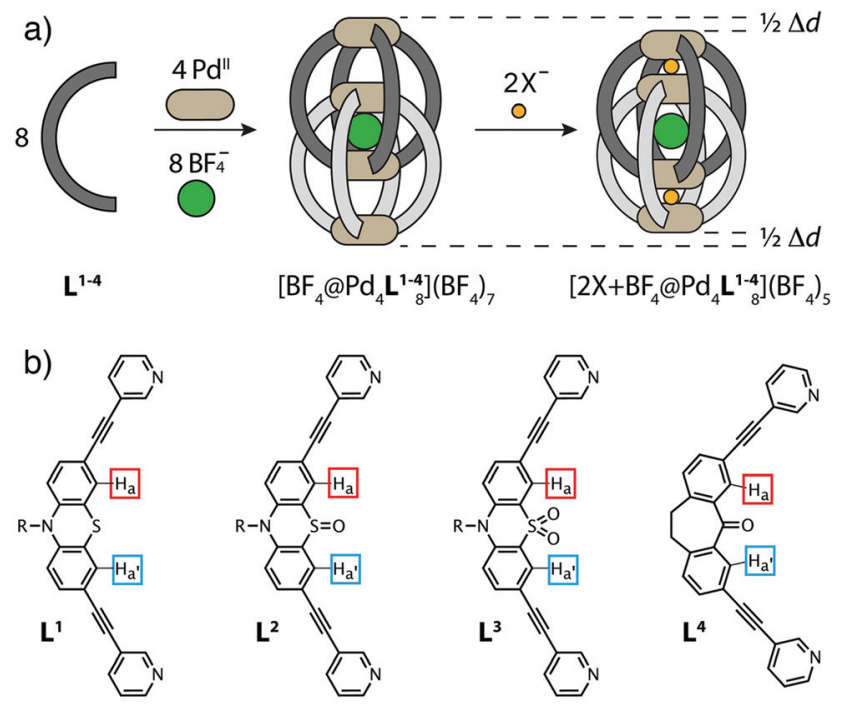

$d(\mathrm{~N}, \mathrm{~N}) 17.616$

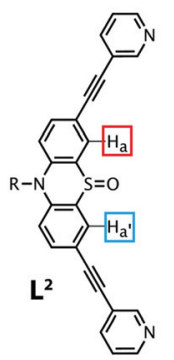

16.786

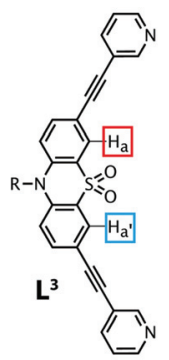

16.548

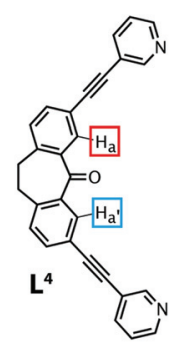

16.343
Fig. 1 (a) Schematic representation of the self-assembly of eight bis-pyridyl ligands $\mathbf{L}^{1-4}$ and four $\mathrm{Pd}(\Perp)$ ions into interpenetrated double-cages $\left[\mathrm{BF}_{4} @ \mathrm{Pd}_{4} \mathrm{~L}^{1-4}{ }_{8}\right]\left(\mathrm{BF}_{4}\right)_{7}(\mathrm{R}=\mathrm{Hex})$. Subsequent binding of two halide anions $\left(\mathrm{X}^{-}=\right.$ $\left.\mathrm{Cl}^{-}, \mathrm{Br}^{-}\right)$in the outer two binding pockets leads to a compression of the doublecages by a host- and guest-dependent value $\Delta d$ (external and loosely bound $\mathrm{BF}_{4}{ }^{-}$counter anions have been omitted for clarity). (b) Chemical structures of ligands $\mathbf{L}^{1-4}$ based on phenothiazine $\left(\mathbf{L}^{1-3}\right)$ and dibenzosuberone $\left(\mathbf{L}^{4}\right)$ backbones. Highlighted in blue and red are the protons $\mathrm{H}_{a}$ and $\mathrm{H}_{\mathrm{a}^{\prime}}$ which were found to be reliable NMR indicators for the degree of cage compression upon halide binding. The given $N, N$-distances are based on double-cage $\mathrm{X}$-ray structures for $\mathbf{L}^{1,2,4}$ and DFT calculation results for $\mathbf{L}^{3}$.

also able to serve as backbone structures for the clean formation of interpenetrated double-cages. ${ }^{8}$

Here, we show that all three phenothiazine-based doublecages are able to bind halide anions $\left(\mathrm{Cl}^{-}\right.$and $\left.\mathrm{Br}^{-}\right)$by replacing the loosely bound $\mathrm{BF}_{4}{ }^{-}$anions in their outer two pockets. Anion binding competition experiments allow us to sort both the cages as well as the anions in the relative order of binding strength. We further show that the degree of the encapsulation-triggered compression of the structure can be monitored by the ${ }^{1} \mathrm{H}$ NMR signal shifts of two characteristic backbone 
protons that are found in all four examined cage derivatives. The data are in accordance with the theoretically determined degree of the structural rearrangement. Following a generalized computational approach, we further show that the relative anion binding strength depends on the size of the ligands (in terms of $\mathrm{N}-\mathrm{N}$ distance).

Three of the four double-cages used in this work are based on $N$-alkylated phenothiazine carrying no $\left(\mathbf{L}^{\mathbf{1}}\right)$, one $\left(\mathbf{L}^{\mathbf{2}}\right)$ or two $\left(\mathbf{L}^{3}\right)$ oxygen substituents attached to its sulphur atom (Fig. 1b). ${ }^{8}$ The fourth double-cage is based on dibenzosuberone $\left(\mathbf{L}^{\mathbf{4}}\right)$, featuring a seven-membered ring with a keto functionality. ${ }^{5 a}$ All cages were assembled using $\left[\mathrm{Pd}\left(\mathrm{CH}_{3} \mathrm{CN}\right)_{4}\right]\left(\mathrm{BF}_{4}\right)_{2}$ as a metal source in acetonitrile. Consequently, the inner pockets of all cages contain one tightly bound $\mathrm{BF}_{4}{ }^{-}$anion, whereas the two $\mathrm{BF}_{4}^{-}$anions in the outer pockets were found to be in quick exchange with the surrounding medium. ${ }^{6}$ In good agreement with our previous findings for $\left[\mathrm{BF}_{4} @ \mathrm{Pd}_{4} \mathbf{L}_{8}{ }_{8}\right]\left(\mathrm{BF}_{4}\right)_{7}$, the addition of two equivalents of halide anions $\left(\mathrm{X}=\mathrm{Cl}^{-}, \mathrm{Br}^{-}\right)$to $\left[\mathrm{BF}_{4} @ \mathrm{Pd}_{4} \mathbf{L}_{8}^{1-3}\right]\left(\mathrm{BF}_{4}\right)_{7}$ results in the formation of a host-guest complex $\left[2 \mathrm{X}+\mathrm{BF}_{4} @ \mathrm{Pd}_{4} \mathbf{L}_{8}^{\mathbf{1 - 3}}\right]\left(\mathrm{BF}_{4}\right)_{5}$ in which the halides occupy the outer two pockets of the double-cage structure (Fig. 1a). ${ }^{5 a}$

Fig. 2 exemplifies the changes in the ${ }^{1} \mathrm{H}$ NMR spectra of ligand $\mathbf{L}^{\mathbf{1}}$ upon double-cage formation and subsequent titration with chloride (for further titrations see the ESI + ). In the double-cage $\left[\mathrm{BF}_{4} @ \mathrm{Pd}_{4} \mathbf{L}_{8}{ }_{8}\right]\left(\mathrm{BF}_{4}\right)_{7}$ all signals are doubled as compared to the spectrum of ligand $\mathbf{L}^{\mathbf{1}}$. Addition of one equiv. of chloride leads to the formation of a new species which exists in a $1: 1$ ratio with the parental cage and can be assigned

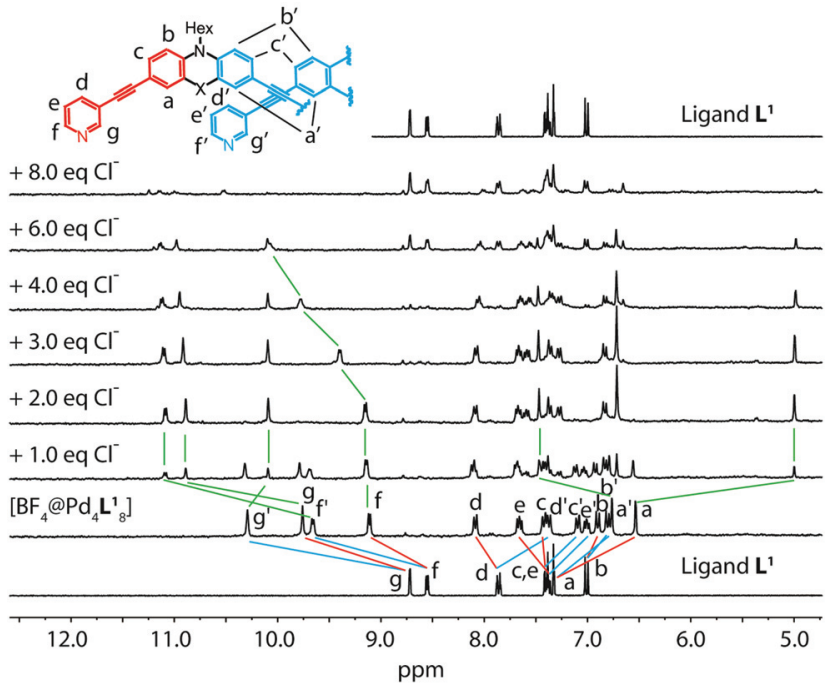

Fig. $2{ }^{1} \mathrm{H}$ NMR titration $\left(300 \mathrm{MHz}, 298 \mathrm{~K}\right.$ ) of a solution of $\left[\mathrm{BF}_{4} @ \mathrm{Pd}_{4} \mathrm{~L}_{8}{ }_{8}\right]\left(\mathrm{BF}_{4}\right)_{7}$ (0.5 mL, $\left.0.35 \mathrm{mM}, \mathrm{CD}_{3} \mathrm{CN}\right)$ with $\mathrm{NBu}_{4} \mathrm{Cl}(17.5 \mathrm{mM})$. Upon the addition of two equivalents of $\mathrm{Cl}^{-}$, a double-cage $\left[2 \mathrm{Cl}+\mathrm{BF}_{4} @ \mathrm{Pd}_{4} \mathrm{~L}_{8}{ }_{8}\right]\left(\mathrm{BF}_{4}\right)_{5}$ having two chloride anions tightly bound in the outer two pockets is formed. No occurrence of an intermediate species containing only one $\mathrm{Cl}^{-}$was observed. Addition of excess chloride first results in a signal shift of the outward pointing protons $\mathrm{H}_{f}$ followed by decomposition of the double-cage and release of free ligand $\mathbf{L}^{\mathbf{1}}$. Highlighted in green colour are the most significant shifts in the NMR spectrum upon addition of the halide anion. to the compound $\left[2 \mathrm{Cl}+\mathrm{BF}_{4} @ \mathrm{Pd}_{4} \mathbf{L}_{8}{ }_{8}\right]\left(\mathrm{BF}_{4}\right)_{5}$ following the previously reported reasoning. ${ }^{5 a}$ Addition of a second equiv. of $\mathrm{Cl}^{-}$converts the residual fraction of $\left[\mathrm{BF}_{4} @ \mathrm{Pd}_{4} \mathbf{L}_{8}{ }_{8}\right]\left(\mathrm{BF}_{4}\right)_{7}$ into the chloride-containing double-cage. Signal shifts characteristic of anion binding are highlighted in green in Fig. 2. Noteworthy is the downfield shift of all protons reaching into the outer cavities $\left(\mathrm{H}_{\mathrm{e}^{\prime}}, \mathrm{H}_{\mathrm{f}^{\prime}}\right.$ and $\left.\mathrm{H}_{\mathrm{g}}\right)$ as well as the downfield shift of the backbone proton $\mathrm{H}_{\mathrm{a}^{\prime}}$ and the tremendous upfield shift of the backbone proton $\mathrm{H}_{\mathrm{a}}$.

The system's behaviour upon further addition of chloride is interesting: first, the signal of the outward pointing proton $\mathrm{H}_{\mathrm{f}}$ starts to gradually shift downfield indicating highly dynamic binding of chloride anions near the outer faces of the $\mathrm{Pd}$ (pyridine) ${ }_{4}$ complexes that border the double-cage structure. Continued addition of chloride eventually leads to disappearance of all cage signals and occurrence of NMR signals of the free ligand which we can explain with chloride acting as a competing ligand for $\operatorname{Pd}($ II) at these concentrations.

Next, we compared the NMR-spectroscopic changes associated with chloride binding with those seen in the binding of bromide. Fig. 3a shows that the ${ }^{1} \mathrm{H}$ NMR spectrum of $[2 \mathrm{Br}+$ $\left.\mathrm{BF}_{4} @ \mathrm{Pd}_{4} \mathbf{L}^{\mathbf{1}}{ }_{8}\right]\left(\mathrm{BF}_{4}\right)_{5}$ shows significantly smaller shifts for the backbone signals $\mathrm{H}_{\mathrm{a}}$ (red) and $\mathrm{H}_{\mathrm{a}^{\prime}}$ (blue) as compared to the species $\left[2 \mathrm{Cl}+\mathrm{BF}_{4} @ \mathrm{Pd}_{4} \mathbf{L}_{8}^{\mathbf{1}}\right]\left(\mathrm{BF}_{4}\right)_{5}$. The same trend was observed for the halide adducts of cages $\left[\mathrm{BF}_{4} @ \mathrm{Pd}_{4} \mathbf{L}_{8}^{3}\right]\left(\mathrm{BF}_{4}\right)_{7}$ (Fig. 3b) and $\left[\mathrm{BF}_{4} @ \mathrm{Pd}_{4} \mathbf{L}_{8}^{\mathbf{4}}\right]\left(\mathrm{BF}_{4}\right)_{7}$ (Fig. 3c). Due to the previously reported signal broadening in the NMR spectra of the

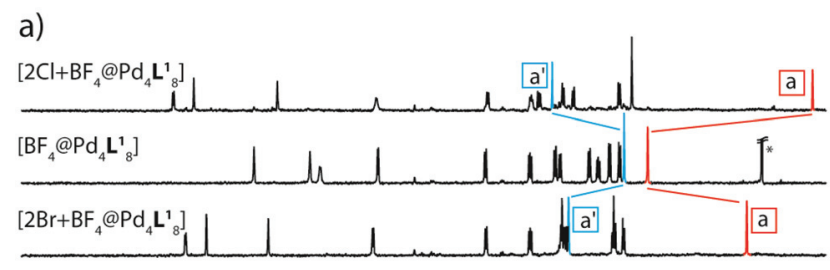

b)

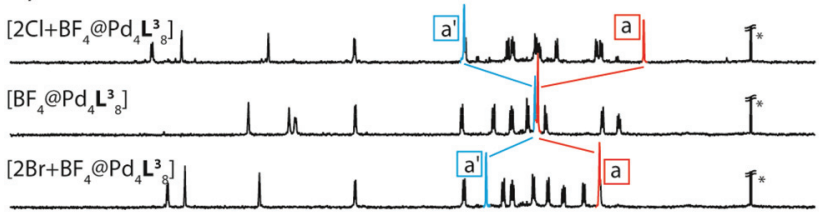

C)

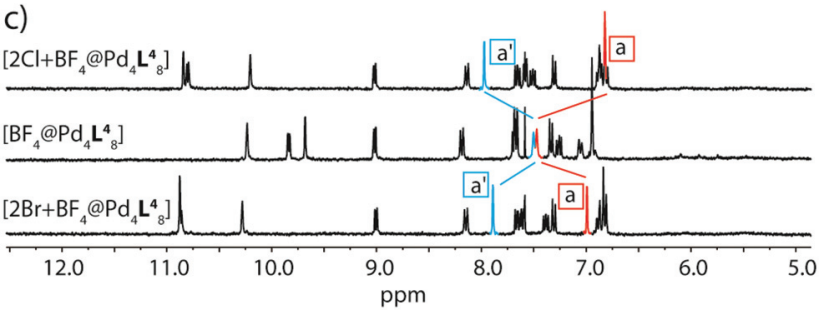

Fig. $3{ }^{1} \mathrm{H}$ NMR spectra (300 MHz, $298 \mathrm{~K}, \mathrm{CD}_{3} \mathrm{CN}$ ) of the cages (a) $\left[\mathrm{BF}_{4} @ \mathrm{Pd}_{4} \mathrm{~L}_{8}{ }_{8}\right]\left(\mathrm{BF}_{4}\right)_{7},(\mathrm{~b})\left[\mathrm{BF}_{4} @ \mathrm{Pd}_{4} \mathrm{~L}_{8}{ }_{8}\right]\left(\mathrm{BF}_{4}\right)_{7}$ and (c) $\left[\mathrm{BF}_{4} @ \mathrm{Pd}_{4} \mathrm{~L}_{8}^{4}\right]\left(\mathrm{BF}_{4}\right)_{7}$ and their halide containing analogues $\left[2 \mathrm{X}+\mathrm{BF}_{4} @ \mathrm{Pd}_{4} \mathrm{~L}_{8}{ }_{8}\right]\left(\mathrm{BF}_{4}\right)_{5}$, $\left[2 \mathrm{X}+\mathrm{BF}_{4} @ \mathrm{Pd}_{4} \mathbf{L}_{8}{ }_{8}\right]-$ $\left(\mathrm{BF}_{4}\right)_{5}$ and $\left[2 \mathrm{X}+\mathrm{BF}_{4} @ \mathrm{Pd}_{4} \mathrm{~L}_{8}{ }_{8}\right]\left(\mathrm{BF}_{4}\right)_{5}\left(\mathrm{X}^{-}=\mathrm{Cl}^{-}, \mathrm{Br}^{-}\right)$. Highlighted in red and blue are the shifts of the $\mathrm{H}_{\mathrm{a}}$ and $\mathrm{H}_{\mathrm{a}^{\prime}}$ protons. ${ }^{*}=$ Impurity. 
cage $\left[\mathrm{BF}_{4} @ \mathrm{Pd}_{4} \mathbf{L}_{8}^{2}\right]\left(\mathrm{BF}_{4}\right)_{7}$, no clear titration results were obtained for this sample. ${ }^{8}$

The fact that bromide binding leads to a smaller change in the chemical shifts of protons $\mathrm{H}_{\mathrm{a}}$ and $\mathrm{H}_{\mathrm{a}^{\prime}}$ as compared to chloride binding can be explained in the following way: halide binding in the outer two pockets causes the two $\left\{\mathrm{Pd}_{2} \mathbf{L}_{4}\right\}$-subunits of the double-cages to shift towards each other by a distance $\Delta d$, because of the smaller size of the halide anions as compared to tetrafluoroborate. The larger ionic radius of the bromide anion results in a smaller compression of the cages and therefore a smaller $\Delta d$ along the $\mathrm{Pd}_{4}$-axis as compared to the chloride species.

As can be seen in Fig. 4, the upfield/downfield shifts of protons $\mathrm{H}_{\mathrm{a}} / \mathrm{H}_{\mathrm{a}^{\prime}}$ result from the movement of these protons towards/away from a nearby pyridine ring plane. The proton $\mathrm{H}_{\mathrm{a}}$ thus experiences an upfield shift while the proton $\mathrm{H}_{\mathrm{a}^{\prime}}$ is downfield shifted. The extent of this signal shift $\Delta \delta$ is dependent on $\Delta d$; hence bromide causes smaller shifts than chloride.

Subsequently, we compared the binding-induced NMR signal shifts among the cages $\left[\mathrm{BF}_{4} @ \mathrm{Pd}_{4} \mathbf{L}_{8}{ }_{8}\right]\left(\mathrm{BF}_{4}\right)_{7},\left[\mathrm{BF}_{4} @ \mathrm{Pd}_{4} \mathbf{L}_{8}{ }_{8}\right]\left(\mathrm{BF}_{4}\right)_{7}$ and $\left[\mathrm{BF}_{4} @ \mathrm{Pd}_{4} \mathbf{L}_{8}^{4}\right]\left(\mathrm{BF}_{4}\right)_{7}$ (Fig. 3a-c). It was observed that the values of the signal shifts $\Delta \delta$ decrease with decreasing length of the $\left\{\mathrm{Pd}_{2} \mathbf{L}_{4}\right\}$-units in the double cage (see Fig. $1 \mathrm{~b}$ for the $d(\mathrm{~N}, \mathrm{~N})=$ $d(\mathrm{Pd}, \mathrm{Pd})$ distances $)$. Again, this trend can be explained by the amplitude $\Delta d$ of the double-cage compression along the $\mathrm{Pd}_{4}$-axis upon halide binding which is smaller for the shorter cages.

In order to gain a deeper insight into the relationship between the NMR signal shift $\Delta \delta$ and the cage compression $\Delta d$, we computed the theoretical $\Delta d$ values for the chloride and bromide binding of all double-cages according to our previously reported method. ${ }^{7}$ Here, the double-cage system is

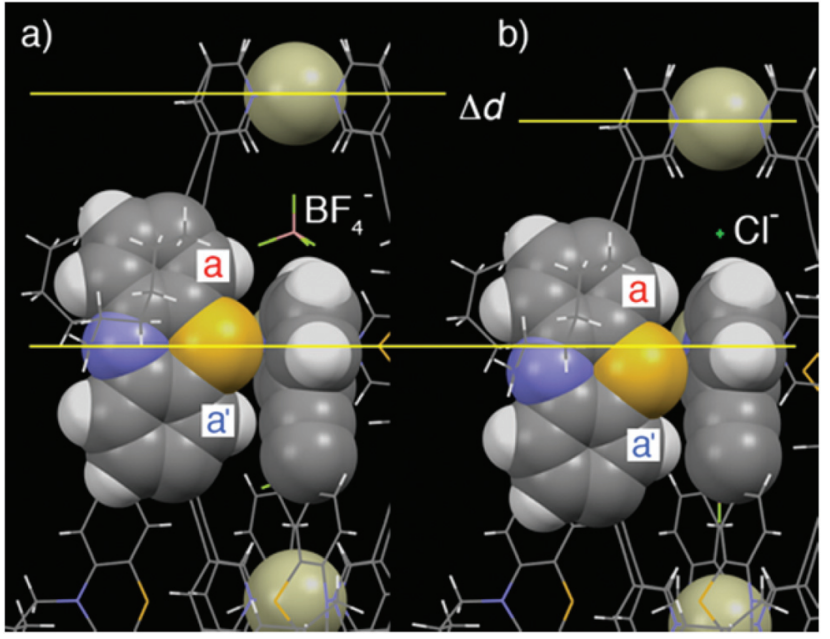

Fig. 4 Comparison of the relative positions of the backbone protons $\mathrm{H}_{\mathrm{a}}$ and $\mathrm{H}_{\mathrm{a}^{\prime}}$ of $\left[\mathrm{BF}_{4} @ \mathrm{Pd}_{4} \mathrm{~L}^{1}{ }_{8}\right]\left(\mathrm{BF}_{4}\right)_{7}$ (a) before chloride binding (based on the previously reported $\mathrm{X}$-ray structure) and (b) after binding of two chloride anions in the outer two pockets (based on NOESY results). The relative movement of the two interdigitated, monomeric $\left\{\mathrm{Pd}_{2} \mathbf{L}_{4}{ }_{4}\right\}$-units by $\Delta d$ along the $\mathrm{Pd}_{4}$-axis moves the proton $\mathrm{H}_{\mathrm{a}}$ closer to and the proton $\mathrm{H}_{\mathrm{a}^{\prime}}$ away from the pyridine ring plane. The observed $\Delta \delta$ is a function of the $\Delta d$ value which is a function of the type of double-cage and halide anion. treated as a simple push-and-pull model in which the three $\operatorname{Pd}(\mathrm{py})_{4}$-anion- $\mathrm{Pd}(\mathrm{py})_{4}$ potentials representing the anion-filled pockets are mechanically coupled by rigid linkers with the lengths of the ligands $\mathbf{L}^{\mathbf{1 - 4}}$. The fitting of the potentials was carried out with the OGOLEM program package (for details see the ESI +$)^{10}{ }^{10}$ The computed values for the largest cage (based on $\mathbf{L}^{\mathbf{1}}$ ) should be considered with caution. In our simplified model, solvent interactions are neglected and each anion is placed equidistant to the two neighbouring $\operatorname{Pd}(\mathrm{py})_{4^{-}}$ planes. In the case of $\mathbf{L}^{\mathbf{1}}$ (distance $d(\mathrm{Pd}, \mathrm{Pd})$ within the $\left\{\operatorname{Pd}_{2} \mathbf{L}_{4}{ }_{4}\right\}$-subunits $\left.=17.616 \AA\right)$, these assumptions may not necessarily apply, as one anion could preferentially bind to one of the planes, maximizing its interaction. This could also allow for additional solvent interactions within the cage. For smaller cage sizes, the error bars become significantly large, as one approaches the minimum well for the $\operatorname{Pd}(\mathrm{py})_{4}$-anion$\mathrm{Pd}(\mathrm{py})_{4}$ interaction, which is rather flat. In the system based on the ligand $\mathbf{L}^{1}$, additional data for estimating the double-cage compression $\Delta d$ was obtained from NOESY experiments according to our previously reported procedure. ${ }^{6}$ Next, doublecage models based on these $\Delta d$ values were constructed and used to calculate the relative ${ }^{1} \mathrm{H}$ NMR shifts $\Delta \delta$ of protons $\mathrm{H}_{\mathrm{a}}$ and $\mathrm{H}_{\mathrm{a}^{\prime}}$ for the examined host-guest complexes with chloride and bromide. Details of the GIAO-DFT calculations can be found in the ESI. $\dagger^{9}$

Fig. 5 compares the experimentally obtained signal shifts $\Delta \delta$ with the calculated shifts based on the theoretical and the NOESY-derived $\Delta d$ values. Qualitative agreement of the experimental with the calculated trends can be observed: in the systems based on ligands $\mathbf{L}^{4}$ and $\mathbf{L}^{3}$, the decrease in $\Delta \delta$ when going from the larger double-cage $\left(\mathbf{L}^{3}\right)$ to the smaller one $\left(\mathbf{L}^{4}\right)$ is reproduced by the calculations. Furthermore, the decrease in $\Delta \delta$ when comparing the binding of the smaller anion $\left(\mathrm{Cl}^{-}\right)$ with the larger anion $\left(\mathrm{Br}^{-}\right)$is also in good agreement with the experimental data. In the case of the largest double-cage $\left[\mathrm{BF}_{4} @ \mathrm{Pd}_{4} \mathbf{L}_{8}^{1}\right]\left(\mathrm{BF}_{4}\right)_{7}$, only the $\Delta \delta$ values based on the NOESY

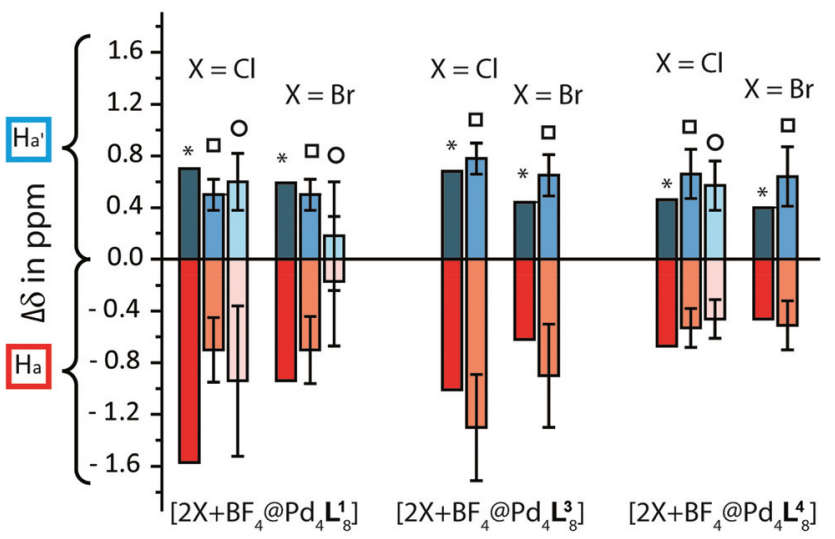

Fig. 5 Comparison of the $\Delta \delta$ values of protons $\mathrm{H}_{\mathrm{a}}$ and $\mathrm{H}_{\mathrm{a}^{\prime}}$ extracted from the NMR spectra $\left(^{*}\right)$ and theoretically derived from the computed ( $\square$ ) and the NOESY-based $(O)$ double-cage compression $\Delta d$. Data are shown for the chloride and bromide binding of the double-cages based on the ligands $\mathbf{L}^{\mathbf{1}}, \mathbf{L}^{\mathbf{3}}$ and $\mathbf{L}^{\mathbf{4}}$. See the ESIt for details of the calculations. 
Table 1 Results of the competition experiments for the binding of $\mathrm{Cl}^{-}$and $\mathrm{Br}^{-}$, respectively, in a series of all possible binary double-cage combinations. The arrows point in the direction of the stronger binder for each individual experiment

\begin{tabular}{lllll}
\hline & {$\left[\mathrm{BF}_{4} @ \mathrm{Pd}_{4} \mathbf{L}_{8}{ }_{8}\right]$} & {$\left[\mathrm{BF}_{4} @ \mathrm{Pd}_{4} \mathbf{L}_{8}{ }_{8}\right]$} & {$\left[\mathrm{BF}_{4} @ \mathrm{Pd}_{4} \mathbf{L}_{8}{ }_{8}\right]$} & {$\left[\mathrm{BF}_{4} @ \mathrm{Pd}_{4} \mathbf{L}_{8}{ }_{8}\right]$} \\
\hline$\left[\mathrm{BF}_{4} @ \mathrm{Pd}_{4} \mathbf{L}_{8}{ }_{8}\right]$ & - & $\uparrow$ & $\uparrow$ & $\uparrow$ \\
{$\left[\mathrm{BF}_{4} @ \mathrm{Pd}_{4} \mathbf{L}^{2}{ }_{8}\right]$} & $\leftarrow$ & - & $\leftarrow \uparrow$ & $\uparrow$ \\
{$\left[\mathrm{BF}_{4} @ \mathrm{Pd}_{4} \mathbf{L}_{8}^{3}\right]$} & $\leftarrow$ & $\leftarrow / \uparrow$ & - & $\uparrow$ \\
{$\left[\mathrm{BF}_{4} @ \mathrm{Pd}_{4} \mathbf{L}_{8}{ }_{8}\right]$} & $\leftarrow$ & $\leftarrow$ & $\leftarrow$ & - \\
\end{tabular}

data were found to be in qualitative agreement with the chemical shift data extracted from the NMR titration experiments.

Next, we studied the relative anion affinity of all the discussed double-cages by ${ }^{1} \mathrm{H}$ NMR-based competition experiments. ${ }^{11}$ For this purpose we prepared all possible binary double-cage combinations in NMR tubes and added 1 equiv. of the halide anion $\left(\mathrm{Cl}^{-}\right.$or $\left.\mathrm{Br}^{-}\right)$. From the obtained spectra we could deduce whether one of the cages has a stronger affinity to bind the halide anion or both the cages have roughly equal affinities (see the ESI + ). The results of these experiments are shown in Table 1.

The following order of relative binding magnitude was obtained:

$\left[\mathrm{BF}_{4} @ \mathrm{Pd}_{4} \mathbf{L}_{8}^{4}\right] \gg\left[\mathrm{BF}_{4} @ \mathrm{Pd}_{4} \mathbf{L}_{8}^{3}\right] \approx\left[\mathrm{BF}_{4} @ \mathrm{Pd}_{4} \mathbf{L}_{8}^{2}\right]>\left[\mathrm{BF}_{4} @ \mathrm{Pd}_{4} \mathbf{L}_{8}{ }_{8}\right]$

This order was observed for chloride binding as well as for bromide binding. Furthermore, halide anion competition experiments indicated that $\mathrm{Cl}^{-}$and $\mathrm{Br}^{-}$are bound with equal affinities by cages $\left[\mathrm{BF}_{4} @ \mathrm{Pd}_{4} \mathbf{L}^{1,3}{ }_{8}\right]\left(\mathrm{BF}_{4}\right)_{7}$ (see the ESI $\dagger$ ). Surprisingly, the double-cage based on the shortest ligand $\left(\mathbf{L}^{4}\right)$ binds $\mathrm{Cl}^{-}$much stronger than $\mathrm{Br}^{-}{ }^{5 a}$ These results are consistent with precipitation experiments using $\mathrm{AgBF}_{4}$ (see the ESI†). ${ }^{6}$

Most interestingly, the observed order in binding affinity follows the order of the cage size (in terms of Pd-Pd distance within the $\left\{\mathrm{Pd}_{2} \mathbf{L}_{4}\right\}$-subunits) with the shortest cage $\left[\mathrm{BF}_{4} @ \mathrm{Pd}_{4} \mathbf{L}_{8}^{\mathbf{4}}\right]\left(\mathrm{BF}_{4}\right)_{7}$ showing the highest binding affinity and the longest cage $\left[\mathrm{BF}_{4} @ \mathrm{Pd}_{4} \mathbf{L}_{8}{ }_{8}\right]\left(\mathrm{BF}_{4}\right)_{7}$ showing the smallest.

This observation raised the questions whether there is an ideal cage size for maximizing the halide anion binding affinity and whether a bromide selective receptor can be designed based on the double-cage architecture. ${ }^{12}$ Therefore, we applied our push-and-pull model to compute the halide binding energy considering a wide range of double-cage sizes under variation of the distance $d(\mathrm{~N}, \mathrm{~N})(=d(\mathrm{Pd}, \mathrm{Pd}))$ within the $\left\{\mathrm{Pd}_{2} \mathbf{L}_{4}\right\}$-subunits.

The results are plotted in Fig. 6. The energies are given relative to the minimum found for a cage with two chloride anions as a function of cage size $d(\mathrm{~N}, \mathrm{~N})$. As can be seen, chloride will be favoured over bromide, in particular for smaller cages. The optimal cage size (the one where the interaction between the chloride anions and the host is maximised) is found at a value of $d(\mathrm{~N}, \mathrm{~N})=14.8 \AA$. The results agree with our observations that in the range of $d(\mathrm{~N}, \mathrm{~N})=16.343-17.616 \AA$ the anion affinity increases with decreasing cage size. In the case of bromide, the optimal $d(\mathrm{~N}, \mathrm{~N})$ is found at about $15.4 \AA$ A. For larger

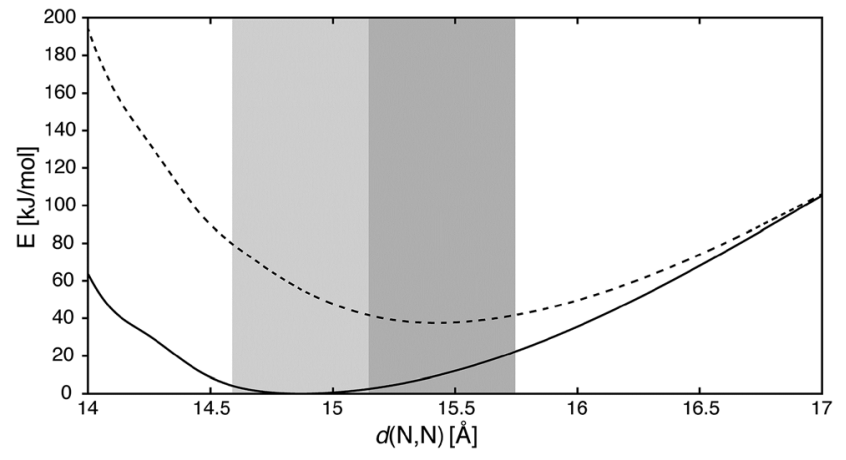

Fig. 6 Computed affinity for the exchange of both $\mathrm{BF}_{4}{ }^{-}$anions in the outer two pockets with chloride (solid line) and bromide (dashed line) as a function of the $\mathrm{Pd}-\mathrm{Pd}$ separation $\mathrm{d}(\mathrm{N}, \mathrm{N})$ in the $\left\{\mathrm{Pd}_{2} \mathbf{L}_{4}\right\}$-subunits in a series of hypothetical double-cage species $\left[\mathrm{BF}_{4} @ \mathrm{Pd}_{4} \mathbf{L}_{8}\right]$. The optimal cage size for chloride binding is smaller than that for bromide binding. In particular for small cages, chloride binding is stronger than bromide binding (grey areas indicate a region with $1 \mathrm{kcal} \mathrm{mol}^{-1}$ deviation from the minimum).

distances, our model predicts that the profile of both anions will become identical. In this regime, the distance to each Pd (py)-4-plane is becoming so significant that the interaction will become purely Coulombic in nature (both anions behave as point charges and above $17 \AA$ their interaction profiles overlap). This trend is in good agreement with the experimental observations presented above. Again, one should take into consideration that our model will break down for larger cage systems, as the anion could possibly bind preferentially on one side and be further stabilised by solvent interactions.

In conclusion, we presented the ability of three phenothiazine-based, interpenetrated coordination cages to bind chloride and bromide in their outer two pockets. We found that the structural changes between these three derivatives, which are a consequence of the oxidation state of the ligand's sulphur atoms, influence the size of the pockets and therefore the binding affinities towards halide anions. In comparison, the examined dibenzosuberone-based system binds chloride significantly stronger than bromide. Furthermore, the halide binding affinity was found to decrease with increasing cage size, which is in good agreement with theoretical results. Our findings may be of relevance for the further development of selective anion binders and nanomechanical devices.

M.F. thanks the Evonik Foundation for a PhD fellowship. We thank the DFG (CL 489/2-1) and the FCI for financial support. We thank Ilker Balcioglu, Lorenz Deres, David Engelhard, Prof. Dr Christian Griesinger and Dr Michael John for help with the NMR measurements and Dr Holm Frauendorf for the ESI measurements.

\section{Notes and references}

1 (a) N. Gimeno and R. Vilar, Coord. Chem. Rev., 2006, 250, 3161; (b) J. L. Sessler, P. Gale, W.-S. Cho and S. J. Rowan, Anion Receptor Chemistry (Monographs in Supramolecular 
Chemistry), Royal Society of Chemistry, Cambridge, 2006; (c) S. O. Kang, J. M. Llinares, V. W. Day and K. BowmanJames, Chem. Soc. Rev., 2010, 39, 3980.

2 (a) M. D. Pluth and K. N. Raymond, Chem. Soc. Rev., 2007, 36, 161; (b) S. J. Dalgarno, N. P. Power and J. L. Atwood, Coord. Chem. Rev., 2008, 252, 825; (c) D. J. Tranchemontagne, Z. Ni, M. O'Keeffe and O. M. Yaghi, Angew. Chem., Int. Ed., 2008, 47, 5136; (d) R. Chakrabarty, P. S. Mukherjee and P. J. Stang, Chem. Rev., 2011, 111, 6810; (e) T. K. Ronson, S. Zarra, S. P. Black and J. R. Nitschke, Chem. Commun., 2013, 49, 2476.

3 M. Han, R. Michel, B. He, Y.-S. Chen, D. Stalke, M. John and G. H. Clever, Angew. Chem., Int. Ed., 2013, 52, 1319.

4 See also: (a) M. Fukuda, R. Sekiya and R. Kuroda, Angew. Chem., Int. Ed., 2008, 47, 706; (b) R. Sekiya, M. Fukuda and R. Kuroda, J. Am. Chem. Soc., 2012, 134, 10987.

5 (a) S. Freye, J. Hey, A. Torras-Galán, D. Stalke, R. HerbstIrmer, M. John and G. H. Clever, Angew. Chem., Int. Ed., 2012, 51, 2191; (b) S. Freye, R. Michel, D. Stalke, M. Pawliczek, H. Frauendorf and G. H. Clever, J. Am. Chem. Soc., 2013, $135,8476$.
6 S. Freye, D. M. Engelhard, M. John and G. H. Clever, Chem.-Eur. J., 2013, 19, 2114.

7 J. M. Dieterich, G. H. Clever and R. A. Mata, Phys. Chem. Chem. Phys., 2012, 14, 12746.

8 M. Frank, J. Hey, I. Balcioglu, Y.-S. Chen, D. Stalke, T. Suenobu, S. Fukuzumi, H. Frauendorf and G. H. Clever, Angew. Chem., Int. Ed., 2013, DOI: anie.201302536.

9 J. S. Mugridge, R. G. Bergman and K. N. Raymond, J. Am. Chem. Soc., 2011, 133, 11205-11212.

10 (a) J. M. Dieterich and B. Hartke, Mol. Phys., 2010, 108, 279; (b) J. M. Dieterich and B. Hartke, J. Comput. Chem., 2011, 32, 1377.

11 G. H. Clever, W. Kawamura and M. Shionoya, Inorg. Chem., 2011, 50, 4689.

12 For examples of bromide and/or chloride selective receptors see: (a) H. Miyaji and J. L. Sessler, Angew. Chem., Int. Ed., 2001, 40, 154; (b) B. Schazmann, N. Alhashimy and D. Diamond, J. Am. Chem. Soc., 2006, 128, 8607; (c) J.-M. Chen, X.-M. Zhuang, L.-Z. Yang, L. Jiang, X.-L. Feng and T.-B. Lu, Inorg. Chem., 2008, 47, 3158; (d) V. K. Gupta, R. N. Goyal and R. A. Sharma, Electrochim. Acta, 2009, 54, 4216. 